\title{
Numerical Study of Shaft-Seal Parameters for Various Geometry Configurations and Operation Regimes
}

\author{
Petr Straka, ${ }^{1, *}$ \\ ${ }^{1}$ VZLU - Czech Aerospace Research Centre, Beranových 130, 19905 Prague 9, Czech Republic
}

\begin{abstract}
The contribution deals with numerical modelling of flow through the shaft labyrinth seal for various geometric configurations and operating states. The objective is to obtain dependency of the mass flow rate through the seal and the outlet flow angle from the seal on the pressure ratio and the rotation speed for various seal clearances and other geometrical parameters. The results will be used as a background for modification of the test-rig for axial turbine stage.
\end{abstract}

\section{Introduction}

In order to reduce the problem complexity the aerodynamic and energy properties of the axial turbines are usually investigated (theoretically, experimentally, numerically) using simplified models. One of the simplest among these models is the linear (or straight) blade cascade, which represents an unrolled circumferential section of the axial blade wheel (see e.g. $[1,2]$ ). A little more complex is model of one separated blade wheel without any effect of surrounding blade wheels or other flow-parts of the axial blade machines. The model of single axial turbine stage, composed from stator and rotor blade wheels, represents a natural extension the complexity of previous model. The experimental test rig was built for measurement of the aerodynamic and energy properties of the axial turbine stages $([4,5]$, fig. 1$)$.

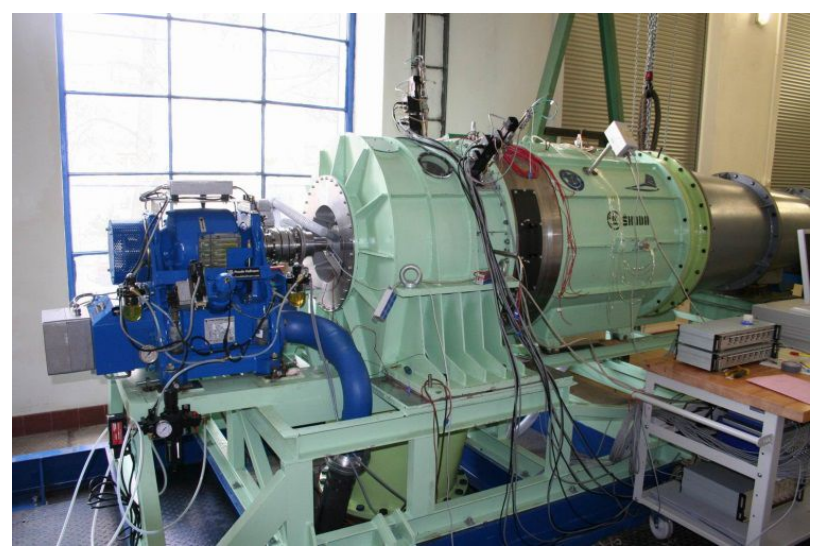

Fig. 1. Turbine test rig.

This test rig was then used for investigation of several axial turbine stages in single-stage configuration (details can be found in $[6,7])$.

In case of multistage configuration, the flow field in the axial turbine stage is affected by flow through the foregoing stages. This effect is particularly apparent in peripheral parts of the blade-span as a consequence of the secondary flows. Therefore, the existing test rig has been modified to be able to set the inlet flow parameters (the turbulent intensity and the span-wise velocity profile) in order to simulate the effect of foregoing turbine stages [9]. Subsequently the ability of the test rig has been extended for measuring of so called one and half stage configuration. The one and half stage represents further complexity extension of previous single stage model. This model consists of one axial turbine stage (stator and rotor wheel) followed with next stator wheel. That configuration allows catching the effect of the foregoing turbine stage on the flow field in subsequent stator blade wheel $[10,11]$.

One of the significant effects, that influences the flow in peripheral parts of the blade-span, is the outlet stream from the labyrinth-seal (shaft seal at the root part or shroud seal at the tip part). For this reason, the effort is to extend the test rig capability to include the effect of the shaft- and shroud-labyrinth-seal. The construction of mentioned test rig is such that the rotor blades are carried on the rotating disc. In case of the axial turbine stage in the drum-type rotor configuration, the rotating drumtype rotor is replaced by the stationary hub wall (see e.g. [7]), which allows to simplify the design and remove some problems with the rotor dynamics. Similarly, the shaft-seal can be designed as rotary with rotating sealfins and the bottom wall connected with the rotor disc (fig. 2 left) or as stationary with neglecting of the sealfins and the bottom wall rotation (fig. 2 right). Design with rotary shaft-seal may lead to problems with the rotor dynamics because of the additional mass of the rotor disc, whereas design with stationary shaft-seal is much simpler for realization. On the other hand the loss of the rotary effect may have a significant impact on the mass flow rate through the seal and on the outlet angle from the seal.

\footnotetext{
Corresponding author: straka@vzlu.cz
} 

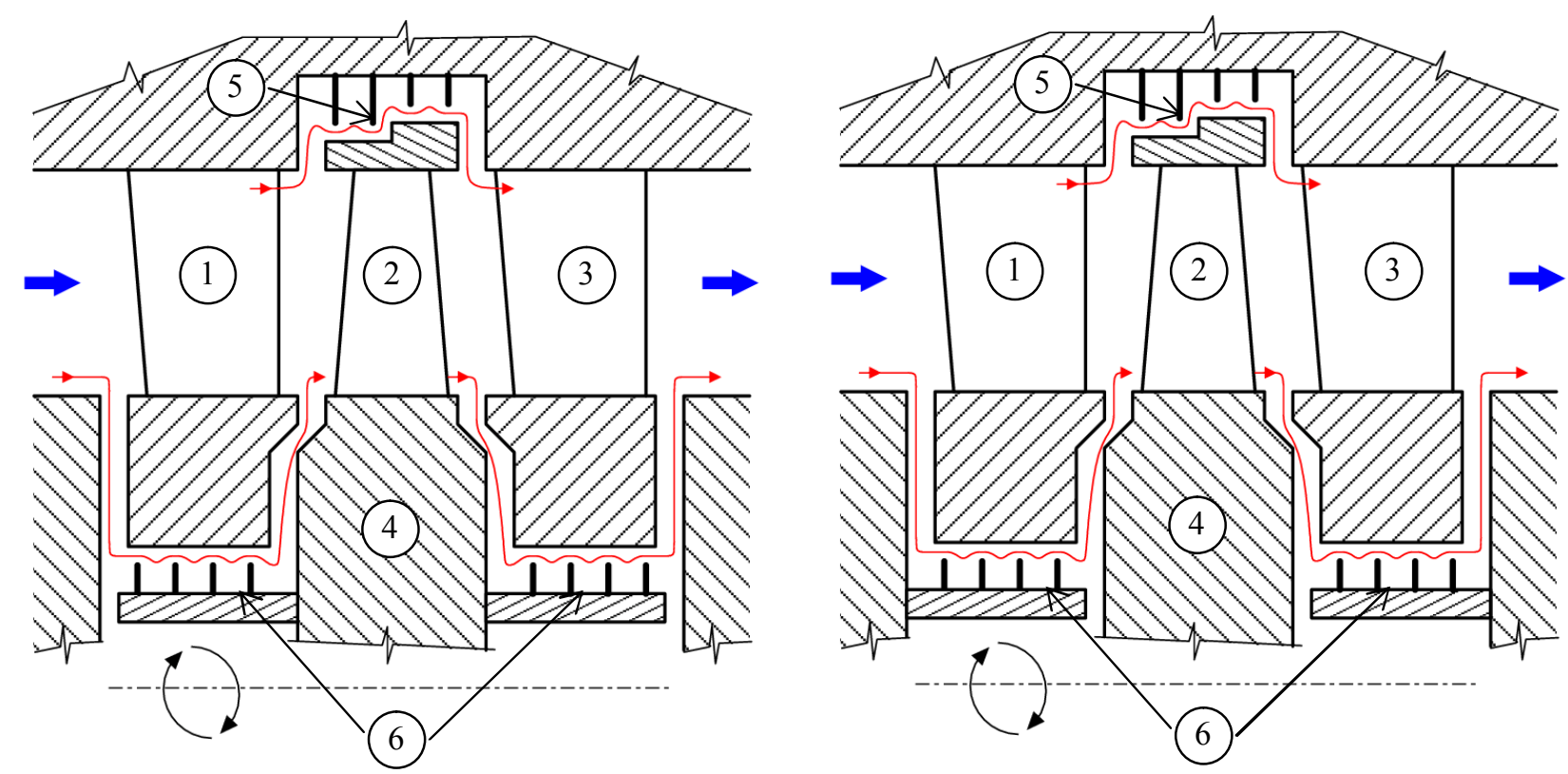

Fig. 2. Scheme of the one and half stage with rotary shaft-seal (left) and stationary shaft-seal (right); 1 - first stator blade, 2 - rotor blade, 3 - second stator blade, 4 - rotor disc, 5 - shroud-seal, 6 - shaft-seal.

Numerical simulation of flow through simplified model of the shaft-seal was carried out as a basic background for selection of variant with rotary or stationary shaft-seal. The numerical simulation was performed for various clearances, pressure ratios, rotation speeds and number of seal-fins in configurations with rotary and stationary seal. In fig. 2, the flow-paths through the labyrinth seals are depicted. Let us look on the shaft-seal now. After passing the area of seal-fins the stream flows in radial direction along the rotor disc. Length of this radial part is given by structural limitations of the test rig and is much longer than in real configuration with the drum-type rotor (fig. 3). Therefore, in order to describe the effect of the rotor disc on conditions inside the shaft-seal, the numerical simulation was carried out also for geometrical configuration which is close to the real configuration with the drum-type rotor.

Figure 4 shows scheme of the simplified shaft-seal model with description of the boundaries. The outer shaft diameter is for all configurations $\varnothing d_{1}=220 \mathrm{~mm}$,

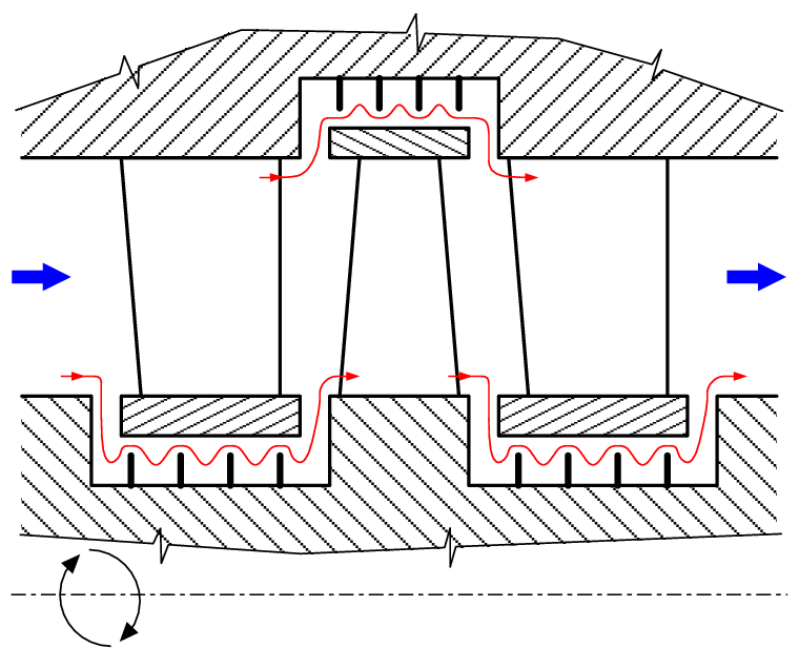

Fig. 3. Scheme of real configuration with the drum-type rotor. diameter of the bottom wall is $\varnothing d_{2}=177.5 \mathrm{~mm}$ for the test rig configuration and $\varnothing d_{2}=206.5 \mathrm{~mm}$ for real configuration, the seal-clearance is $c=0.4,0.8,1.2 \mathrm{~mm}$, pitch of the seal-fins is $b=6 \mathrm{~mm}$ for the test rig configuration and $b=7.5 \mathrm{~mm}$ for real configuration, the height of the seal area is $h=4.5 \mathrm{~mm}$ for all configurations, number of seal-fins is 3,4 and 5 for the test rig configuration, in case of real configuration only 4 seal-fins was studied. The thickness of the seal-fins is $0.3 \mathrm{~mm}$.

\section{Numerical results}

Flow through the shaft-seal is modelled as steady, compressible, turbulent flow of the ideal gas. The flow field in presented configurations can be supposed as axisymmetric. This means that it could be modelled using the quasi two-dimensional model of the axisymmetric flow in the cylindrical coordinate system. However, it is planned in following work to investigate

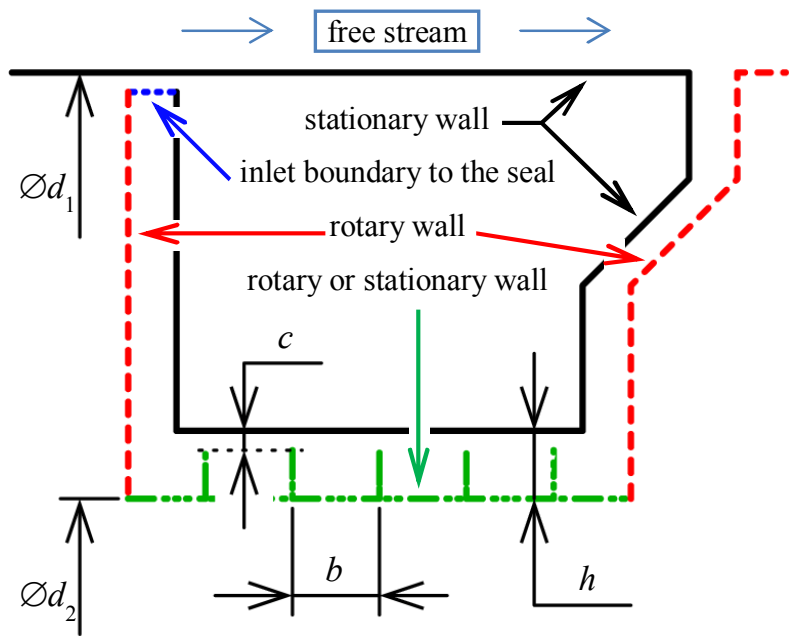

Fig. 4. Scheme of simplified model of the shaft-seal. 
general 3D configurations - interaction with the rotor blades, spatial deformations of the seal-fins, etc. Therefore the flow is modelled as $3 \mathrm{D}$ in the Cartesian coordinate system from the beginning. In fig. 4 there is shown the computational domain meridian. 3D computational domain takes angular section related to one pitch of the first stator blades.

At the inlet boundary to the shaft-seal there are prescribed the total pressure $p_{T}=102 \mathrm{kPa}$, the total temperature $T_{T}=300 \mathrm{~K}$, turbulence intensity $T u=2.2 \%$, ratio of the turbulent to the molecular viscosity $\mu_{t} / \mu=100$ and radial flow direction. The total pressure and temperature of the free stream are the same as at the inlet boundary to the shaft-seal. Flow direction of the free stream is axial. The free stream velocity corresponds to the static to total pressure ratio. The computations were carried out for the static to total pressure ratio in range $0.778 \leq p_{S} / p_{T} \leq 0.975$, rotation speed of the rotating walls in range $900 \leq \mathrm{RPM} \leq 5100$.

Calculations of flow were performed using the in-

a)

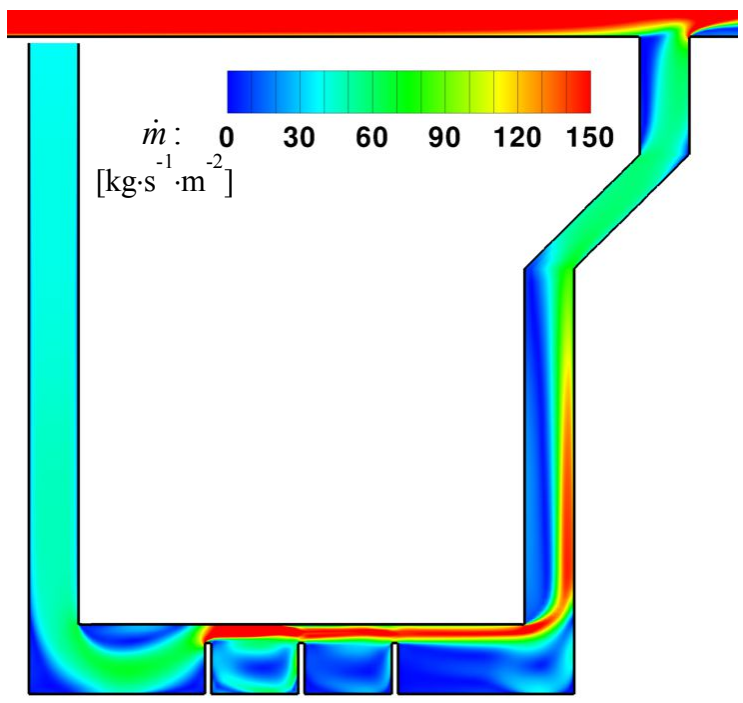

b)

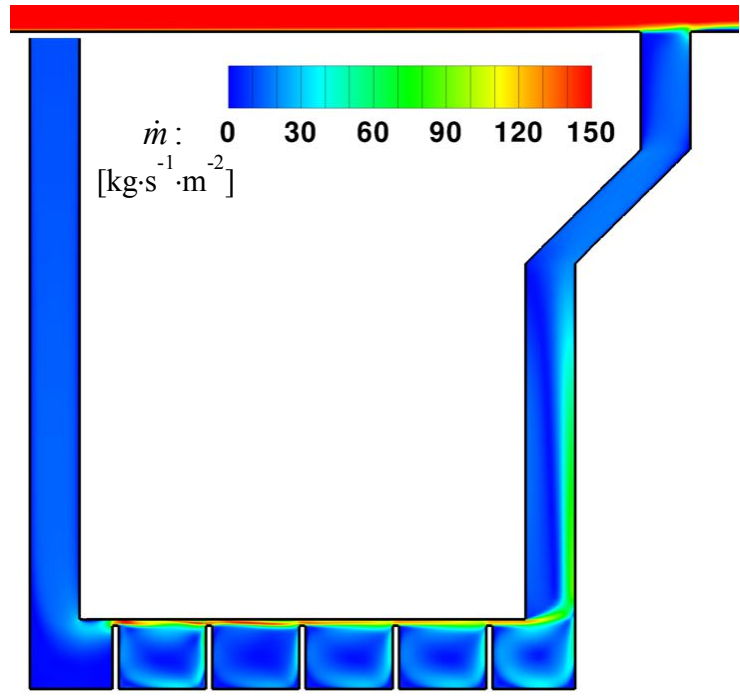

house numerical software, which is based on solution of RANS equations closed with two-equations turbulence model (for more details see [12, 13, 14]). The nonlinear explicit algebraic model of the Reynolds stress is used in this work [15].

The computational domain is discretized by multiblock structured computational mesh of hexahedral cells (detail in fig. 5c). The computational mesh is refined close to the walls to ensure that the viscous sub-layer is covered at least by five cells.

Fields of the mass flux density along the meridian plane for the pressure ratio $p_{S} / p_{T}=0.778$ and $900 \mathrm{RPM}$ are shown in fig. $5 \mathrm{a}, 5 \mathrm{~b}$ and $5 \mathrm{~d}$. The mass flux density along the meridian plane is defined as

$$
\dot{m}=\sqrt{\left(\rho u_{a x}\right)^{2}+\left(\rho u_{\text {rad }}\right)^{2}},
$$

where $\rho$ is the density, $u_{a x}$ and $u_{\text {rad }}$ are axial and radial velocity vector components respectively. Parts a) and b) of fig. 5 shows configuration of the test rig whereas the real configuration is shown in parts d), e) and f). Figure $5 \mathrm{e}$ shows projection of the stream lines to the meridian

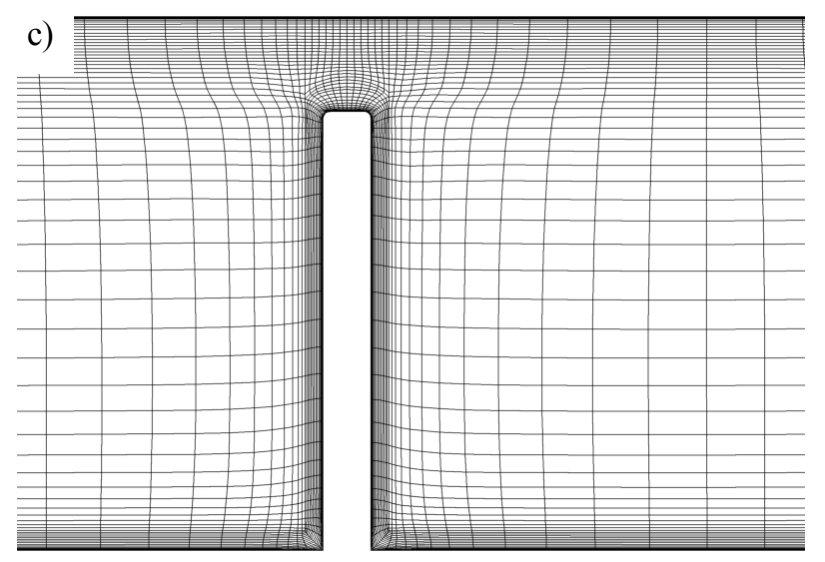

d)

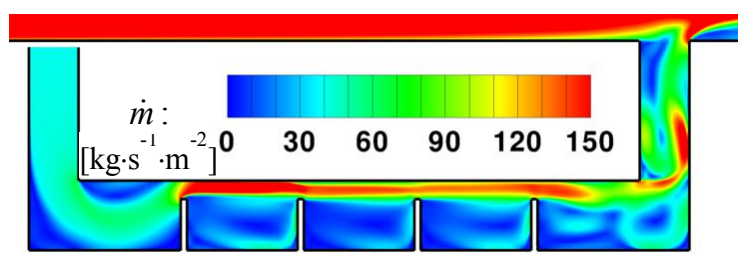

e)

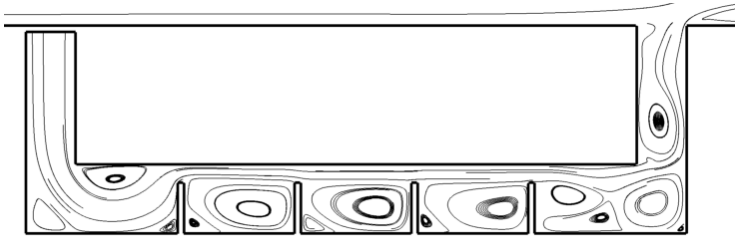

f)

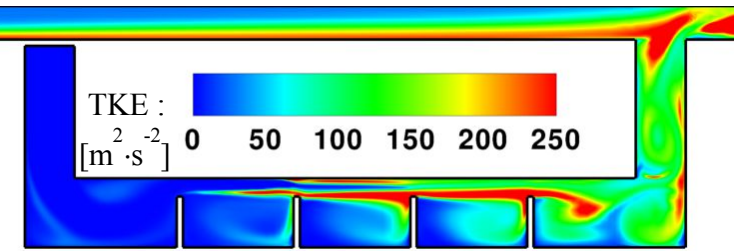

Fig. 5. a) mass flux density, test rig configuration, 3 seal-fins, seal clearance $1.2 \mathrm{~mm}$; b) mass flux density, test rig configuration, 5 seal-fins, seal clearance $0.4 \mathrm{~mm}$; c) detail of the computational mesh around the seal-fin tip; d) mass flux density, real configuration, 4 seal-fins, seal clearance $1.2 \mathrm{~mm}$; e) meridian stream lines projection, real configuration, 4 seal-fins, seal clearance $1.2 \mathrm{~mm}$; f) turbulent kinetic energy, real configuration, 4 seal-fins, seal clearance $1.2 \mathrm{~mm}$. All flow fields: $900 \mathrm{RPM}, p_{S} / p_{T}=0.778$. 
plane. Field of the turbulent kinetic energy (TKE) is shown in fig. 5f. A comparison of figs. 5a and 5b illustrates the difference of flow rate through the shaftseal in configuration with the lowest number of the sealfins and with the widest seal clearance and in configuration with highest number of the seal-fins and with the narrowest seal clearance. Note that all flow fields presented in fig. 5 corresponds to the case with rotating seal-fins and bottom wall.

The dependency of the mass flux $Q$ through the shaft-seal on various geometric and operating parameters is shown in fig. 6 for several investigated cases. It is clear that the mass flux increases with increasing size of the seal clearance, with the decreasing number of the seal-fins, with the decreasing pressure ratio and with the decreasing speed of rotation. Further it can be found that the dependency of the mass flux on the seal clearance,
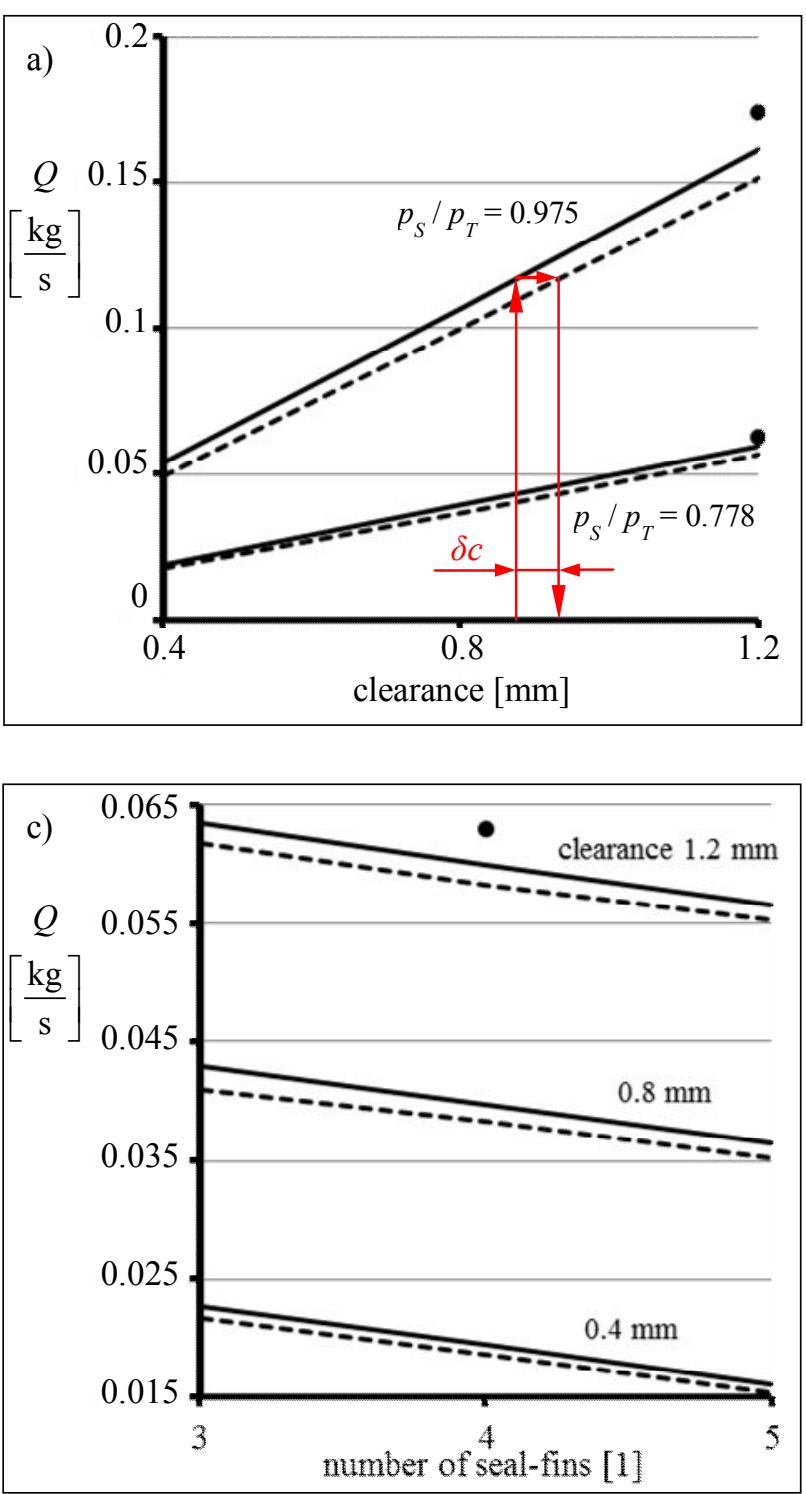

on the number of the seal-fins and on the rotation speed is linear. The effect of rotation of the seal-fins and the bottom wall is such that the mass flux through the stationary shaft-seal is higher than the mass-flux through the rotary shaft-seal. The difference between the mass flux through the stationary and rotary shaft-seal increases with increasing of the rotation speed.

From chart in fig. 6a it is evident that the mass flux through the stationary shaft-seal for given seal clearance corresponds with the rotary shaft-seal of enlarged seal clearance of $\delta c$. It has been found that this imaginary enlargement of the seal clearance in case of the stationary shaft-seal does not exceed $9 \%$ in investigated range of the rotation speed and the pressure ratio. It may be noted that the higher mass flux through the shaft-seal in the real configuration compared to the case of the test rig configuration is given by the fact that the seal
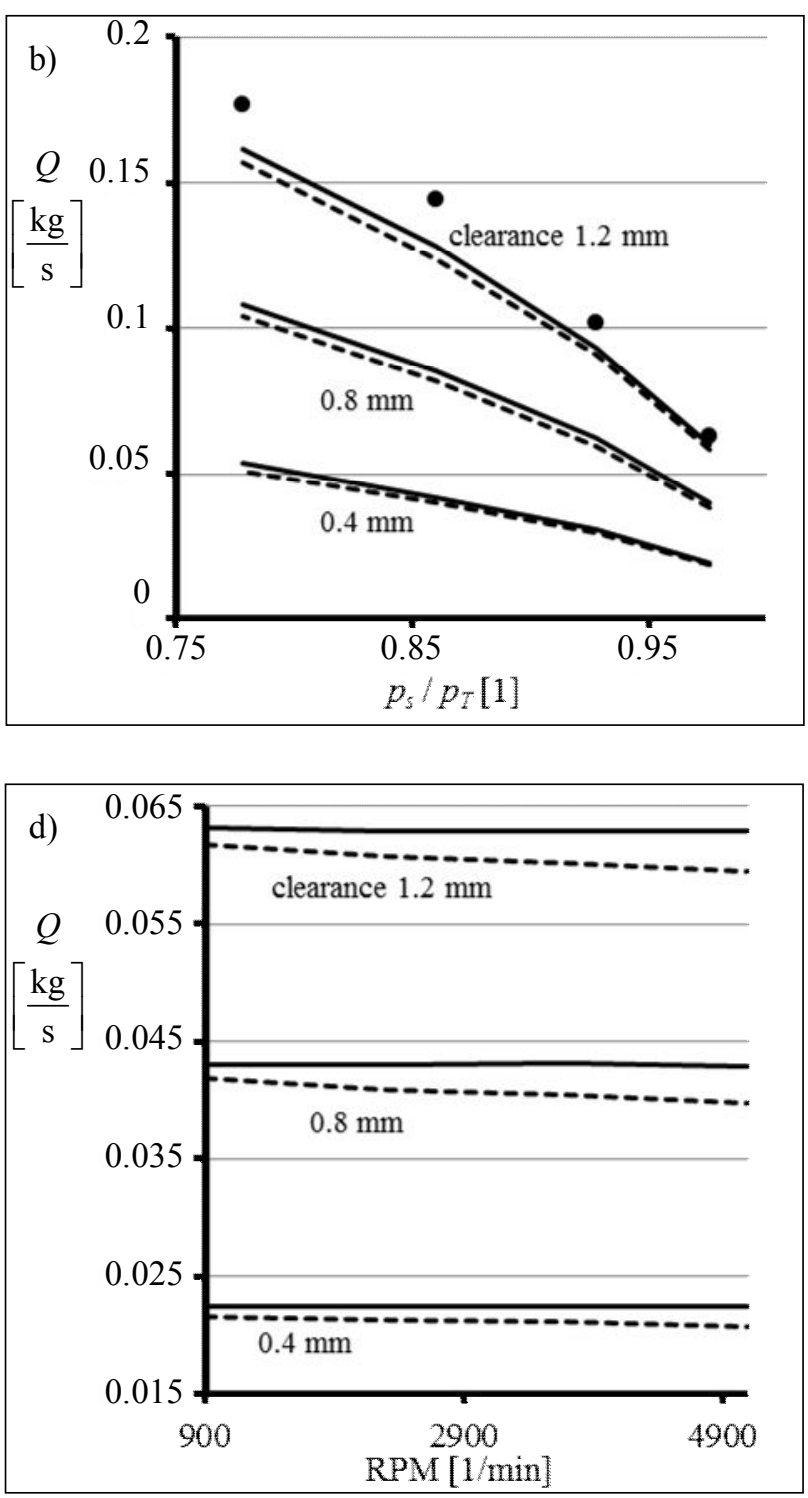

lines: the test rig configuration with stationary ( $(-)$ ) or rotary (----- ) shaft-seal points: real configuration with rotary shaft-seal $(\bullet)$

Fig. 6. a) mass flux dependency on the seal clearance for variant of 4 seal-fins, 5100 RPM and two values of the pressure ratio; b) mass flux dependency on the pressure ratio for variant of 3 seal-fins, 900 RPM and three values of the seal clearance; c) mass flux dependency on number of the seal-fins for variant of $900 \mathrm{RPM}, p_{S} / p_{T}=0.975$ and three values of the seal clearance; d) mass flux dependency on the rotation speed for variant of three seal-fins, $p_{S} / p_{T}=0.975$ and three values of the seal clearance. 
clearance is on higher diameter in the real configuration, therefore the through-flow area is larger.

Another observed parameter besides the mass flux is the flow angle $\psi$ at the outlet from the shaft-seal. This angle is defined as deflection from the radial direction as illustrates fig. 7. The dependency of the deflection angle $\psi$ on various geometric and operating parameters is shown in fig. 8 for some chosen variants. As expected, the deflection angle $\psi$ grows with rising the rotation speed, decreases with decreasing of the pressure ratio, with increasing of the seal clearance and with decreasing the number of the seal-fins. In other words, the deflection angle $\psi$ decreases with decreasing of the mass flux through the shaft-seal. This trend is shown in fig. 9 and fig. 10. Note that the points in fig. 9 are drawn for

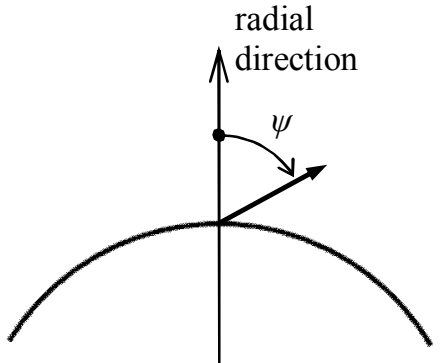

Fig. 7. Deflection angle definition.

various pressure ratios, various seal clearances and various number of the seal-fins. Similarly as in case of the mass flux also the deflection angle $\psi$ from the stationary shaft-seal corresponds with the deflection
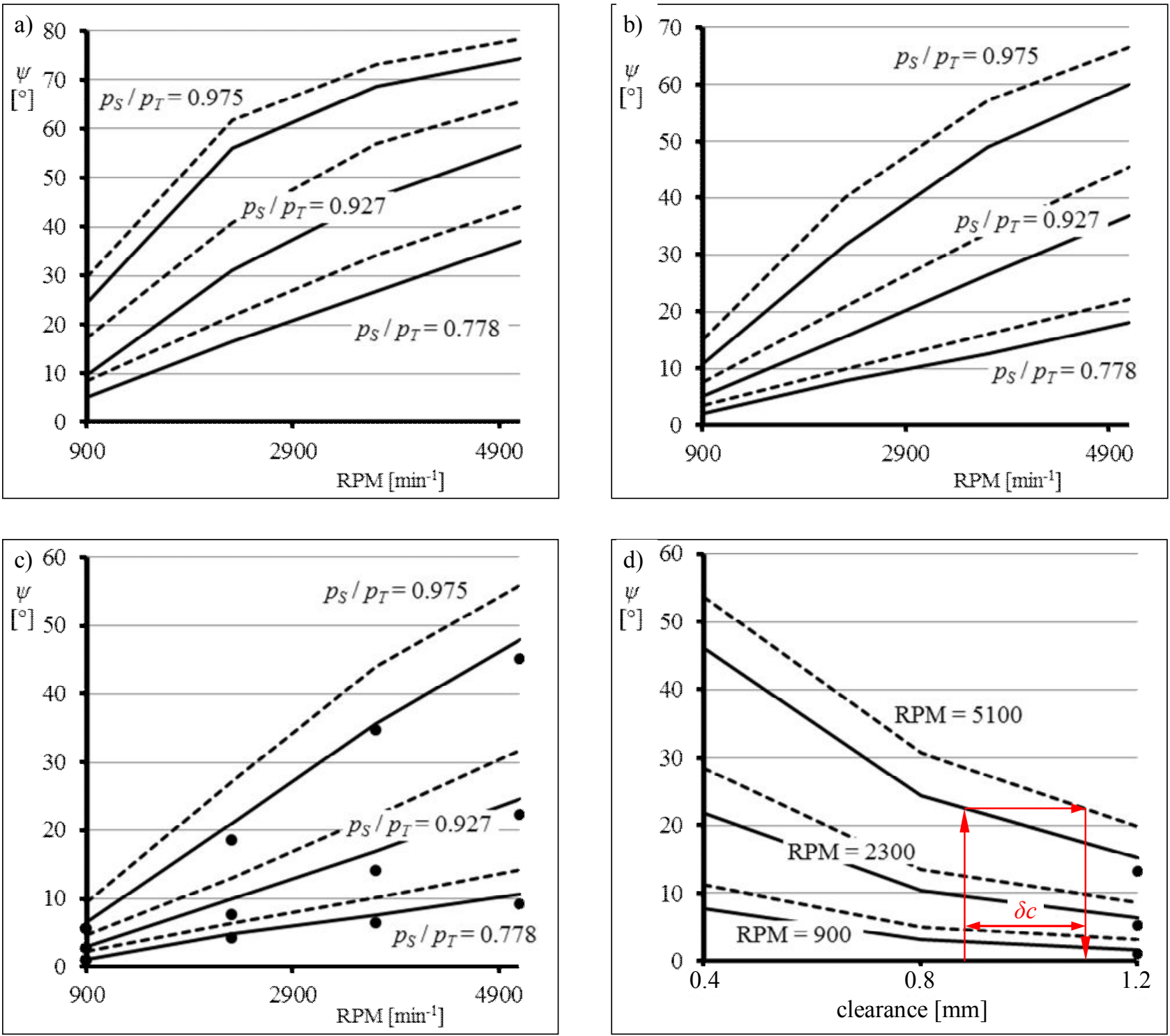

lines: the test rig configuration with stationary (_- ) or rotary ( ---- ) shaft-seal points: real configuration with rotary shaft-seal (

Fig. 8. a) deflection angle dependency on the rotation speed for variant of 4 seal-fins, seal clearance $0.4 \mathrm{~mm}$ and three values of the pressure ratio; b) deflection angle dependency on the rotation speed for variant of 4 seal-fins, seal clearance $0.8 \mathrm{~mm}$ and three values of the pressure ratio; c) deflection angle dependency on the rotation speed for variant of 4 seal-fins, seal clearance $1.2 \mathrm{~mm}$ and three values of the pressure ratio; d) deflection angle dependency on the seal clearance for variant of 4 seal-fins, $p_{S} / p_{T}=0.860$ and three values of the rotation speed. 


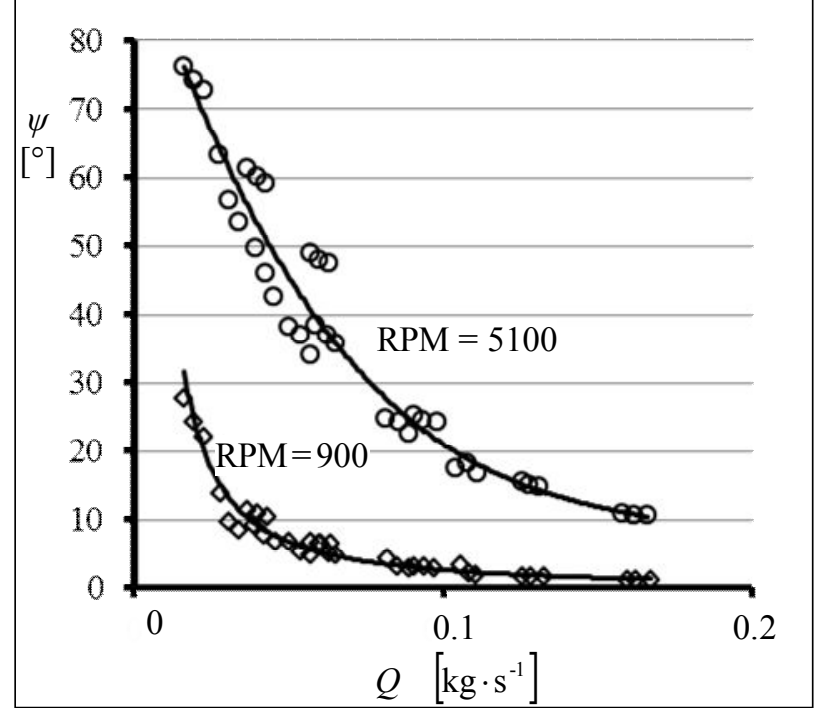

Fig. 9. Dependency of the deflection angle on the mass flux test rig configuration, stationary shaft-seal, two rotation speed (points are for various pressure ratios, various seal clearance and various number of the seal-fins).

angle from the rotary shaft-seal with enlarged seal clearance about $\delta c$ as shown in fig. 8d. Furthermore, it can be stated that the deflection angle from the rotary shaft-seal is significantly larger (up to ten degrees) compared to the stationary shaft-seal, which is an effect of the rotating rotor disc. The deflection angle from the stationary shaft-seal is much closer to the case of the real configuration as shown in figures $8 \mathrm{c}$ and $8 \mathrm{~d}$.

\section{Conclusions}

The results of numerical calculation of flow through the shaft-seal in the test rig configuration show that:

- the mass flux through the rotary shaft-seal is lower than the mass flux through the stationary shaft-seal at the same geometric and operating conditions,

- the deflection angle at the outlet from the rotary shaft-seal is larger than in case of the stationary shaft-seal at the same geometric and operating conditions,

- the flow properties of the stationary shaft-seal correspond to the rotary shaft-seal with enlarged seal clearance at the same operating conditions,

- the flow properties of the stationary shaft-seal correspond better to properties of the real configuration compared to properties of the rotary shaft-seal.

Based on obtained results it will be possible to propose the stationary shaft-seal with enlarged seal clearance to preserve the same mass flux as in case of the real configuration where the influence of the shaftseal rotation on the deflection angle at the outlet from the seal will be substituted by the effect of the rotor disc. The configuration of the stationary shaft-seal is useful with respect to prevent of some problems with the rotor dynamics, also with respect to much simpler

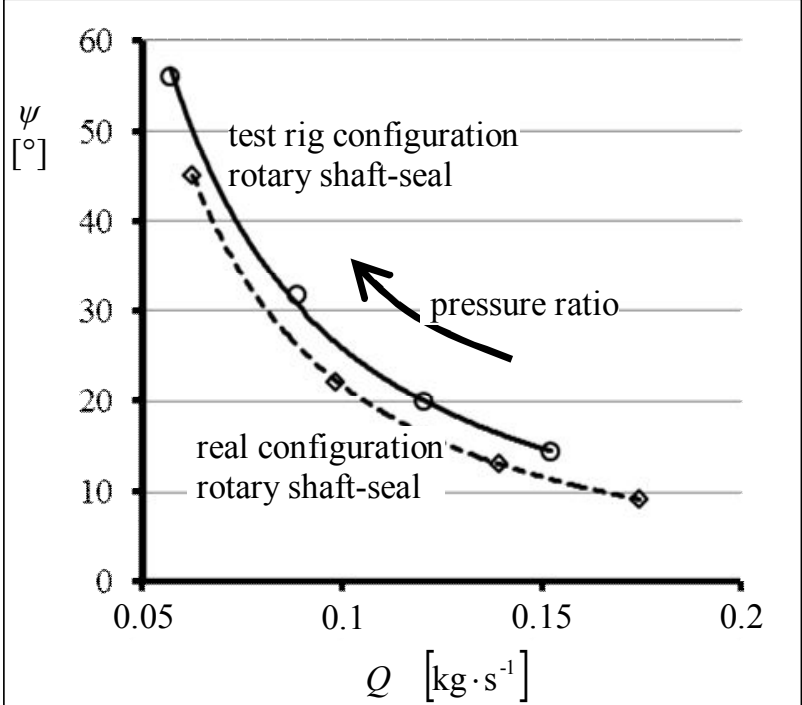

Fig. 10. Dependency of the deflection angle on the mass flux four seal-fins, 5100 RPM, seal clearance $1.2 \mathrm{~mm}$.

construction of the test rig and with respect to much more accurate concentric seating of the seal-fins.

\section{Acknowledgement}

This work was supported by the project TH02020086 of the Technology Agency of the Czech Republic and by the Long-term Framework Advancement Plan provided by the Ministry of Industry and Trade of the Czech Republic.

\section{References}

1. T. Jelínek, P. Straka, M. Kladrubský, Applied Mechanics and Materials, 821, pp. 48-56 (2016)

2. M. Němec, P. Straka, T. Jelínek, M. Babák, ASME paper GT2010-22490 (2010)

3. M. Němec, J. Michálek, V. Strach, The XVIII Symposium on Measuring Techniques in Turbomachinery, Thessaloniki (2006)

4. T. Jelínek, M. Němec, Proc. Conf. EFM 2011, pp. 706-716, Jičín (2011)

5. M. Němec, T. Jelínek, M. Babák, ASME paper GT2012-69693 (2012)

6. P. Straka, M. Němec, T. Jelínek, EPJ, 92, 02088 (2015)

7. T. Jelínek, M. Němec, V. Uruba, Proc. Conf. Eng. Mechanics 2016, pp. 254-257, Svratka (2016)

8. M. Němec, T. Jelínek, P. Milčák, Proc. Conf. PSE 2017, Pilsen (2017)

9. M. Němec, T. Jelínek, P. Milčák, Proc. Conf. EFM 2017, Mikulov, (2017, in-press)

10. P. Straka, EPJ Web of conferences, 25, 01090 (2012)

11. P. Straka, Report VZLÚ R-5904, Prague (2013), (in Czech)

12. P. Straka, Report VZLÚ R-4910, Prague (2010), (in Czech)

13. C.L. Rumsay, T.B. Gatski, Jour. Of Aircraft, 83, pp. 904-910 (2001) 